\title{
Daring the Meaning, or Cyberspace that Matters. Criticism-Creativity and Online Education
}

\author{
Edyta Just \\ Linköping University, Linköping, Sweden \\ Email: edyta.just@liu.se,edytajust@gmail.com
}

How to cite this paper: Just, E. (2018). Daring the Meaning, or Cyberspace that Matters. Criticism-Creativity and Online Education. Creative Education, 9, 2016-2036. https://doi.org/10.4236/ce.2018.913147

Received: September 4, 2018

Accepted: October 22, 2018

Published: October 25, 2018

Copyright $\odot 2018$ by author and Scientific Research Publishing Inc. This work is licensed under the Creative Commons Attribution International License (CC BY 4.0).

http://creativecommons.org/licenses/by/4.0/

\begin{abstract}
This paper focuses on online education and generic competences such as criticism and creativity. It brings to the fore theories that address processes of meaning making (i.e., a psychological constructionist account of the brain basis of emotion-the conceptual act model (Lindquist et al., 2012; Barrett et al., 2014) and reflect on various patterns of meaning making comprising those that lead to criticism and creativity (i.e., the Deleuzian and Guattarian (1987; 2009) philosophical accounts of affect, concept and stratum) to inspire pedagogical practices that aim to create critically-creative abilities among students. Concomitantly, it seeks to reflect on how such pedagogical undertakings can be actualized in online education and on the possibilities online environment offers to promote criticism and creativity among graduates. By posing questions related to teaching methods, learning activities, software and hardware, and their combinations in online education, and by addressing and problematizing concepts and phenomena of immersion and DFI-digital facial image, I will make an effort to not only highlight, what I call, the promises of cyberspace, but also ponder on how the aforementioned pedagogical practices can be actualized online.
\end{abstract}

\section{Keywords}

Generic Competences, Criticism and Creativity, Online Education, Cyberspace, Immersion, DFI-Digital Facial Image

\section{Introduction}

The ability to be critical and creative constitutes an important generic skill that should be acquired by students during their academic training (Waaldijk \& Just, 2010). In the article "Daring to Dare-Theoretical Experiment for Pedagogical 
Practices and Body-Brain-Embedded Subject" (2016), I suggest that criticism and creativity can be approached as an ability to challenge and problematize meaning of the experienced external and internal sensations including experience of emotions, to become surprised, to generate and conjure new meaning, which is new forms of thinking, feeling and acting, and to continually dare it. Indisputably, my particular take on criticism and creativity, influenced by the theories by Lindquist et al. (2012), Barrett et al. (2014), Deleuze and Guattari $(1987,2009)$, is one of the many possible yet, I do believe that the ability to reflect on and question meaning of the experienced sensations, to welcome surprise and to dare creating new meanings (new forms of thinking, feeling and acting)is crucial if one wants to ethically and constructively face the present cultural, social, political, environmental and economic challenges.

The question that remains is how to promote an achievement of such skill by students? How to support students in challenging meaning of the experienced external and internal sensations, in becoming astounded and in creating new meaning - that is new ways of thinking, feeling and acting? Which pedagogical practices to use to do so? And, even more timely given the constant growth of online teaching and learning, which pedagogical practices to use in online educational context?

I am convinced that theories, especially those that address and advance an understanding of meaning making processes, may inspire the ways one thinks about criticism and creativity, and can inform educational practices. Two theories, which I work with, have significantly influenced my thinking about criticism and creativity. Importantly, they have also become an inspiration for pedagogical undertakings, which hopefully can assist students in becoming critical and creative. The first theory is known as psychological constructionist account of the brain basis of emotion-the conceptual act model (Lindquist et al., 2012; Barrett et al., 2014). This theory addresses process of meaning making of external and internal sensations. The second concerns the Deleuzian and Guattarian (1987; 2009) philosophical accounts of affect, concept and stratum, and provides a substantial reflection on various patterns of making meaning including those that lead to novel, yet sustainable ways of thinking, feeling and doing.

In this article I aim to present how those theories influence my thinking about criticism and creativity, and can motivate pedagogical practices that aim to help students to develop critical-creative abilities. In order to do that, I briefly discuss the aforementioned theories and present the results of the theoretical experiment in which they become combined together. Then, I discuss how those theories alone and when experimentally brought together can set off pedagogical practices which then can hopefully result in critical-creative abilities among students. It is crucial to sign that the outline of the theories, the presentation of the results and the discussion concerning the pedagogical practices are based on the article "Daring to Dare" (Just 2016). Importantly, however, due to the aforesaid development of online education, I will also seek to reflect on how the peda- 
gogical undertakings, which can motivate students' criticism and creativity, can be actualized in online context, and on the possibilities online environment offers to promote criticism and creativity amongst students. By posing questions related to content, teaching methods, learning activities, software and hardware, and their combinations in online education, and by addressing and problematizing concepts and phenomena of immersion and DFI-digital facial image, I will make an attempt to reflect on and debate the possibilities of teaching and learning criticism and creativity in online educational context.

\section{Meaning Making-Criticism and Creativity}

In this sub-section of the article I will provide a short yet substantial and comprehensive overview of the theories that I predominately focus on, namely, a psychological constructionist account of the brain basis of emotion-the conceptual act model (Lindquist et al., 2012; Barrett et al., 2014) and the Deleuzian and Guattarian (1987; 2009) philosophical accounts of affect, concept and stratum, and present the outcomes of the theoretical experiment in which they become joined together. ${ }^{1}$ The brief overview of the theories and the presentation of the results of the theoretical experiment will be followed by a paragraph highlighting how those theories separately and when combined together can inspire pedagogical undertakings that intend to create critical-creative abilities among students.

A psychological constructionist account of the brain basis of emotion-the conceptual act model (Lindquist et al., 2012; Barrett et al., 2014) is a neuroscientific theory that concerns the processing of external (exteroceptive sensory information) and internal, bodily sensations (interoceptive sensory information) by the brain. According to this theory, to make meaning of the experienced external and internal sensations is to create a situated conceptualization that is to link external and internal sensations with accumulated knowledge (conceptual knowledge) determining what the sensory input "is, why it is, and what to do with it” (Barrett et al., 2014: p. 451). Crucially, emotions also stand for situated conceptualizations and they "emerge when people make meaning out of sensory input from the body and from the world using knowledge of prior experiences" (Lindquist et al., 2012: p. 123). Conceptual knowledge for a given category develops for properties, relations, rules, other objects, setting, actions, words, events or internal states related to that category (Barrett et al., 2014: p. 452). To make meaning of sensorial input the brain uses the conceptual knowledge to

\footnotetext{
${ }^{1}$ For an extensive description of the theories and the theoretical experiment, please consult the article Just, E. (2016), "Daring to Dare-Theoretical Experiment for Pedagogical Practices and Body-Brain-Embedded Subject." For more on the discussed psychological constructionist account of the brain basis of emotion-the conceptual act model, please consult the following publications: Barrett, L. F. (2006). "Solving the emotion paradox: categorization and the experience of emotion"; Barrett, L. F. (2009). “The Future of Psychology: Connecting Mind to Brain”; Barrett, L. F. (2012). "Emotions are real"; Barsalou, L. W. (2009). "Simulation, situated conceptualization, and prediction"; Lindquist, K., A. \& Barrett, L. F. (2012). "A functional architecture of the human brain: Insights from Emotion"; Russell, J. A. (2003). "Core affect and the psychological construction of emotion."
} 
"create a novel situated conceptualization, integrating current sensory input and retrieved (modal) conceptual knowledge" (Barrett et al., 2014: p. 452). The theory suggests that the past experience, the existing conceptual knowledge play important role in meaning making process. Conceptual knowledge, which one has, is thought about as being able to add new features to and modify sensorial input (Barrett et al., 2014: p. 448). Importantly, however, a present/novel experience can also influence/add to/change existing conceptual knowledge. Crucially, process of meaning making may engender certain internal states and actions. In this sense, this theory not only problematizes the dualism of cognition and affectivity but also undermines the conviction of the separation between thinking, feeling and acting in the brain (Lindquist et al., 2012: p. 142). A creation of a situated conceptualization that is meaning making process entails tight interconnection between thinking, feeling and doing-to make meaning does not only mean to think but also to feel and to do. Moreover, mental causation is said to be probabilistic, namely, it cannot be easily foretold how process of meaning making will proceed and develop. It depends on conceptual knowledge and internal and external sensations how what one experiences will be conceptualized. One's experience, embodiment and embeddedness (past and present) play an important role in process of meaning making. With regard to emotions this indicates that an experienced internal sensation may or may not be conceptualized as an emotion. Furthermore, if an internal sensation becomes conceptualized as an emotion then how this emotion becomes conceptualized (whether it is conceptualized as fear or anger or joy, etc.) depends on, to repeat briefly, conceptual knowledge, sensations and on how external and internal sensations and conceptual knowledge become linked in the brain (Lindquist et al., 2012; Barrett et al., 2014).

For Deleuze and Guattari (2009), "[t]hinking is thought through concepts (...) or sensations and no one of these thoughts is better than another, or more fully, completely, or synthetically 'thought.' (...) The [two] thoughts intersect and intertwine (...)" (2009: p. 198). The brain stands for "a faculty of concepts (...) the faculty of their creation" yet, "[s]ensation is no less brain than the concept" (2009: p. 211). Thus, the brain is both a concept and a sensation. A concept "has an irregular contour defined by the sum of its components (...) being a matter of articulation, of cutting and cross-cutting" (2009: p. 16); it is "a heterogenesis (...) in a state of survey $(\ldots)$ in relation to its components, endlessly traversing them according to an order without distance" (2009: p. 20). Concept or conceptual becoming might be then approached as a creation of new meaning and novel sense concomitantly embodying in itself, so to say, a desire for a constant movement engendering forever rejuvenating meaning and sense. A sensation or an affect is "a zone of indetermination, of indiscernibility" (2009: p. 173) and "otherness caught in a matter of expression" (2009: p. 177). It "contracts the vibrations of the stimulant on a nervous surface or in a cerebral volume: what comes before has not yet disappeared when what follows appears" (2009: p. 211). Sensation/affect or sensory becoming can be then comprehended, among its 
other possible readings, as a moment of deterritorialization, suspension, hesitation, surprise, wonder, and a lack of meaning. For Deleuze and Guattari, concepts and sensations need to interlope (2009: pp. 199, 217). Sensation/affect/ sensory becoming can be read as laying ground for concept/conceptual becoming and securing that conceptual becoming happens and it does not cease to happen-i.e., meaning is always on the move; never finished and complete. As such, conceptual becoming should be interconnected with sensory becoming. With regard to stratum, "[t]he strata are phenomena of thickening on the Body of the earth, simultaneously molecular and molar: accumulations, coagulations, sedimentations, foldings" (Deleuze \& Guattari, 1987: p. 502). Thus, stratum can be understood, among its other readings, as a habitual and customary meaning. Stratum is an ambivalent concept as on the one hand, it seems to contradict criticism and creativity yet, on the other hand, it can support one in enduring and sustaining an experienced indetermination of affect and novelty of concept.

In my theoretical experiment, I propose to approach situated conceptualization as the Deleuzian/Guattarian sensation/affect/sensory becoming, concept/conceptual becoming and stratum. What are then the results of such suggestion?

First of all, associating conceptualization with sensation/affect/sensory becoming reinforces the hypothesis that it may not be easily anticipated how external and internal sensations will become conceptualized. This indicates a rather unpredictable "nature" of the embodied and embedded subject. Secondly, given that sensation/affect/sensory becoming indicates lack of meaning, conceptualization can be seen as potentially turning into a particular surprise or state of the brain's and subject's wonder. Thirdly, to approach conceptualization as concept/conceptual becoming is to strengthen an idea that the brain and so the subject is able to generate new meaning of given sensations, i.e., to create a new combination of external and internal sensations (and actions), and as such create a new conceptual knowledge for a given category that incorporates properties, relations, rules, objects, settings, actions, words, events or internal states related to that category thus, able to think, feel and act differently. Furthermore, as sensation/affect/sensory becoming apparently facilitates concept/conceptual becoming, it can be speculated that once a given input leads to a confusion of the brain (and the subject), such confusion can facilitate a creation of a novel meaning for a given external and/or internal input. Moreover, to think about conceptualization as intertwinement of sensation/affect/sensory and concept/conceptual becoming is to envision it as a state where new meaning is continually engendered and as a state where final meaning is postponed and/or perhaps never reached. As such it seems possible to propose that the brain might be seen not only as being able to produce novel sense, but also postpone creating final meaning of a given sensation. Importantly, associating conceptualization with stratum strengthens an idea of the role the experience may play in meaning making process-pointing out the difficulties of creating new meaning of given sensations, and of challenging and changing the existing conceptual knowledge, 
but also, interestingly, demonstrating that sometimes it can be predicted how certain external and internal sensations will become conceptualized. Finally, approaching conceptualization as necessary intertwinement of sensation/affect/ sensory becoming, concept/conceptual becoming and stratum, where lack of meaning, new meaning and habitual meaning complement each other, may show that for the subject to remain open to indetermination, novelty and change it has sometimes to think in the customarily ways. This is mostly in order to endure and sustain an occurring and experienced lack of meaning and novel sense.

Those two, above outlined theories separately and when experimentally joined together have inspired me to think about criticism and creativity as an ability to challenge and problematize meaning of the experienced external and internal sensations including experience of emotions; to become surprised; to generate and conjure new meaning and to continually dare it.

Yet, how those theories can inspire pedagogical practices that intend to create critical-creative abilities (i.e., to repeat briefly, ability to challenge and problematize meaning of the experienced external and internal sensations; to become surprised; to generate new meaning and to constantly dare it) among students? What should those pedagogical practices aim for?

To begin with, it seems that educators should be attentive to the fact that there might be limits on predicting the outcomes of the meaning making process (i.e., manners of thinking, feeling and acting) among students, and as such educational efforts, undertaken by educators, might not result in the expected outcomes. Secondly, it seems that it might be difficult for pedagogues to encounter students' existing conceptual frameworks though it concomitantly may be possible for them to try to understand, appreciate and challenge students' patterns of conceptualization. Thirdly, it seems that pedagogical undertakings should aim to support students in generating new meanings of external and internal sensations (to help them think, feel and act differently) that is in creating new combinations of external and internal sensations (and actions) and by doing so producing new conceptual knowledge for given categories. How this can be done then? I suggest that "incoming external sensations must be delivered in combinations different from those that students have; different from habitual combinations" (Just, 2016: p. 299). Teachers can make an effort to "challenge with their own actions and words e.g., the rules, relations and actions customarily related to a given category. They can also create events that bridge and expose students to e.g., words/objects/rules related to one category with actions related to another" (ibid.). Furthermore, I also suggest that educators may try to "monitor meaning making of the internal sensations by addressing and talking about them. [They] simultaneously cannot and can predict (an educator's paradox) what internal states and actions they may evoke, yet, they may hope that the created internal states and actions will follow new and daring paths forming (...) new conceptualizations" (ibid.). Importantly, it seems that students should experience a moment of surprise, wonder and lack of meaning in order to be able to generate 
new meaning of given sensations. Furthermore, surprise/wonder/lack of meaning and new meaning should be intertwined in order to secure the fluctuations and movement of meaning. It seems to me that by securing intertwinement of lack of and new meaning, "an educator may hope to activate thinking, feeling and acting that are always on the move, never finished, never taken for granted, and never believed to be final, the only one or finite in their righteousness and certainty" (ibid., p. 300). Intertwinement of wonder, surprise, lack of meaning with new sense, new meaning is also crucial because surprise/lack of meaning may not be productive if endlessly prolonged. It seems then that lack of meaning should be followed by new meaning to prevent students from getting stuck in, so to say, "permanent" meaning-deterritorialization and indetermination. Moreover, it appears that pedagogical practices should also stimulate intertwinement of lack of, new and habitual meaning. As mentioned above too much of wonder/lack of meaning and new meaning may be unsustainable. How then to do that? One suggestion would be to e.g., present students with an input that is simultaneously unknown and familiar or "input that changes over quick succession of time from unknown to familiar and from familiar to unknown or input that may be associated with e.g., two opposite concepts" (ibid.).

To summarize, it seems that pedagogical practices that aim to motivate criticalcreative abilities among students should aim at understanding-appreciatingchallenging students' patterns of conceptualization. Furthermore, they should focus on supporting students in generating new meaning of external and internal sensations (i.e., new conceptual knowledge) and thus, in thinking, feeling and acting differently. Moreover, pedagogical undertakings should try to surprise and make students wonder in order to stimulate a formulation of new meaning but also to allow meaning to tremble and be on the move. At the same time, an infused lack of meaning should indeed be followed by new meaning and sense to prevent students from an endless indetermination. Finally, pedagogical practices should secure students' endurability and sustainability by focusing on intertwining lack of meaning with new meaning and habitual meaning. This is because too much of both lack of meaning and new meaning might be unsustainable for students, colloquially saying: it might be too much to take.

\section{The Promises of Cyberspace}

How then to actualize and materialize such pedagogical practices online?

Before attempting an answer, it is important to acknowledge that much has been written on the specificity of online educational environment, the applied teaching methods and learning activities, and the outcomes of online teaching and learning (e.g., Tu \& McIsaac, 2002; Boler, 2002; Land, 2004; Land \& Bayne, 2005; Lowenthal \& Parscal, 2008; Cobb, 2009; Lowenthal, 2009; Land \& Bayne, 2011; Frisby, Limperos, Record, Downs, \& Kercsmar, 2013; Stack, 2015) including a possible achievement of generic competences (e.g., Gvaramadze, 2012). Despite the fact that the scholarship on online education is broad, and in spite of 
differing approaches to it, it seems to me that two trends somehow dominate when it comes to an assessment of online teaching and learning. Some scholars argue that there is no significant difference between online and offline education with regard to learning outcomes, and that what really matters, is the method and not the media per se: "(...) it is the method and not the media that matters the most in learning effectiveness" (Rovai, 2002: p. 41). Importantly, some other scholars, contend that: “(...) online education cannot possibly replicate the learning that occurs in traditional face-to-face classrooms" (Bejerano, 2008: p. 411). With regard to the outlined approaches, I would be prone to agree with the idea that there might be no difference between online and offline education when it comes to an achievement of learning outcomes. For example, I strongly believe that the ability to be critical and creative (with this ability understood as an ability to challenge and problematize meaning of the experienced external and internal sensations including experience of emotions; to become surprised; to generate and conjure new meaning, and to continually dare it) can be gained by students as in the course of offline as of online education. And yet, contrary to the first approach and more in an alignment with the second one, I would argue that media do matter when it comes to learning outcomes. First of all, applied teaching methods do not function outside of the media but are strongly connected with and quite often conditioned by them, as such media can logically influence the very skill itself. For example, generic competences such as interpersonal and interaction skills, ability to work in a team or ability to motivate people and move towards common goals can certainly be achieved in offline and online teaching and yet, I wonder whether the interpersonal and interaction skills or ability to work in a team, which students obtain while studying online, are exactly the same as those achieved in face to face classrooms? Secondly, while striving to promote a given skill among students, educators have other possibilities (comparing to face to face classrooms) enabled precisely by media to do so-after all online environment differs significantly from offline one.

Given the goals of this article, I will not discuss the extent to which media may influence a given skill-though such discussion is crucial and ultimately necessary. This, however, will be a task for yet another publication. For now, I would like to focus on the thinkable actualization of the previously mentioned pedagogical practices in online educational environment, and on the possibilities that media offer to promote critical-creative abilities among students. Yes, possibilities. I tend to approach specificity of the media and a space they create i.e., cyberspace, not as an obstacle to be overcome, but rather as, precisely, a possibility. In my opinion, the constant attempt to create a so-called social presence ${ }^{2}$ in

${ }^{2}$ There is not a single definition concerning social presence. Social presence online is discussed, among others, in terms of online social interaction, social context, online communication, interactivity, feeling of community, intimacy, immediacy, "making" interactions to resemble those that occur offline, and a degree of perceiving other persons as "real" (degree of salience of the other person in interaction), (Rourke, Anderson, Garrison, \& Archer, 1999; Tu \& McIsaac, 2002; Lowenthal \& Parscal, 2008; Cobb, 2009; Lowenthal, 2009; Frisby, Limperos, Record, Downs, \& Kercsmar 2013). 
online teaching, which is considered to be a facilitator of learning effectiveness and satisfaction, may conceivably indicate, I dare say, rather hostile or at least ambiguous character of cyberspace that needs to be overcome and transformed. Unquestionably, I support and recognize the importance of the efforts undertaken to make students feel as if in offline environment (and this is one of the objectives of creating social presence).Similarly, I am in favour of applying teaching methods that will increase social presence in online teaching, methods that, to mention just few, allow for expression of emotions, humour and self-disclosure, mutual awareness and recognition, sense of belonging; methods that encourage asking questions, promote conversations or rely on collaborations (Lowenthal \& Parscal, 2008; Cobb, 2009). However, supporting as I am towards the creation of social presence in online education, I concomitantly strongly believe that cyberspace is full of affirmative potential that matters when it comes to a promotion of critical-creative abilities amongst students. Certainly, this is not to say that social presence may impair criticism and creativity, but rather to indicate that next to making online environment resemble an offline one, it would also be advisable to focus on the cyberspace potential per se as it might be helpful in promoting criticism and creativity among graduates.

So what has been said about cyberspace? The term cyberspace has been in use since the 80's. Needless to say that there exists an extensive scholarship, which addresses, ethically assesses, problematizes and complexifies the phenomenon and concept of cyberspace. Cyberspace, among others, has become known as the fourth epoch (Stone, 1992); void-like, deep, overflowing, inescapable (Henriksen, 2016); replacement of the physical world of spatial distance (Nunes, 1997); space of imagination and creation of worlds (Siwak, 1997); simulated environment within which it is possible to interact (Featherstone \& Burrows, 1995); immersion in an environment (Featherstone \& Burrows, 1995), and a nowhere-somewhere space that can be entered but has no location (Robins, 1995). Furthermore, it has also been approached as a new universe, "[a] world in which the global traffic of knowledge, secrets, measurements, indicators, entertainments, and alter-human agency takes on form: sights, sounds, presences never seen on the surface of the earth blossoming in a vast electronic night" (Benedikt, 1992 quoted in Bukatman, 1993: p. 193). Moreover, cyberspace has also been described as a space where a sense (and eventually a concept) of identity and lived bodies might bequestioned and challenged (Shapiro \& McDonald, 1992; Bukatman, 1993; Sobchack, 1995; Balsamo, 1996; Boler, 2002; Løvlie, 2005) and a space where people's awareness and understanding of reality can be dared and transformed. In addition, cyberspace has also been thought and written about in terms of violence, crime, abuse, alienation, isolation and loss (Kee, 2005; Citron, 2009; Henriksen, 2016). All in all, cyberspace, as presented above, has become a profoundly discussed and a deeply problematized phenomenon.

Being aware of this complexity and not falling into either an uncritical admiration or an ethically unproblematic appreciation of media and cyberspace, still I 
will try to focus on what I call "the promises of cyberspace" i.e., possibilities media and cyberspace offer to promote critical-creative abilities among students. In particular, I will bring to the fore two concepts or better two cyberspace-phenomena that are: immersion and DFI-Digital Facial Image. By addressing those concepts/phenomena, and by posing questions related to content, teaching methods, learning activities, software and hardware, and their combinations in online education, I will make an effort to not only highlight the promises of cyberspace, but also to ponder on how an educator can actualize the aforementioned pedagogical practices in online context.

\section{Immersion}

The most common way, in which dictionaries tackle the issue of immersion, is to define it as a deep mental involvement in something. A sort of engagement, reverie and subsidence. Apparently cyberspace enables a "cyber-traveller" this kind of an experience. The screen (similarly to a book shape-I dare say) is an entrance gate, the rabbit-hole $e^{3}$ that transports one to another space-time dimension. Once one is in it, one lives it, engages with it, immerses in it. Moreover, the screen allows or better enables a full attention as it frames perception, allures the senses and anchors them in itself with a magnetic force. The full attention may lead to immersion. Yet, the screen is only a start, an invitation to immersion. There must be something that makes one want to live through and engage with what is on the other side of the entrance gate, at the end of the rabbit-hole. There must be something that keeps the senses magnetically anchored. Could it be curiosity? Dean Burnett in his book Idiot Brain. What Your Head Is Really Up To (2016), writes that people are "inherently curious," "drawn to novelty value" and are inclined to explore something novel if there is an opportunity to do so (2016: p. 98). Curiosity, the desire for and interest in something new, in experiencing what is unknown and unfamiliar, apparently can keep one, well, on experiencing! (e.g., Leslie, 2014). But, I want to suggest, this curiosity should be also, so to say, internally oriented: what/who am I? What do I think/feel/do and why? I am unknown to myself and I am curious about myself and so I keep on experiencing (precisely as Alice in Wonderland did). So it seems plausible to propose that to be able to engage and to be attentive thus immersed (once the screen sparks to life) one needs to be curious. But how to become curious? One suggestion might be: relay on unfamiliarity, "speed of change" and interaction. It seems to me that the landscape that is interactive, unfamiliar, highly diverse with many "turns and twists" requires more engagement and attention, and generates more curiosity, including self-curiosity, than the monotonous one. And cyberspace, to which a screen leads, may facilitate the creation of unfamiliar/unknown, and generate interaction, speed of change, turns and twists, and so, ultimately, an immersion. It seems to me that twists and turns, interaction, engagement, attention and

${ }^{3}$ From this paragraph on I will be occasionally using the following expressions: the rabbit-hole, Alice, and Wonderland which are taken from and concomitantly refer to the book Alice's Adventures in Wonderland by Lewis Carroll (1865). 
(self-) curiosity can help students to wonder (and allow meaning to tremble and to be on the move) concomitantly supporting them in acquiring an ability to challenge and problematize meaning of the experienced external and internal sensations, be surprised, generate new meaning and ceaselessly dare it on the level of thinking, feeling and doing. As such, I approach immersion, understood here as "twists and turns," interaction, engagement, attention and (self-) curiosity as the cyberspace's promise; as the offer an educator can use to promote criticism and creativity among students.

Another take on immersion is related to the work on and discussions about virtual reality (VR). Virtual reality,

Is a computer-generated visual, audible and tactile multi-media experience. Using stereo headphones, head-mounted stereo television goggles ("eyephones") able to stimulate three-dimension, wired gauntlets ("datagloves") and computerized clothing ("data suits"), VR aims to surround the human body with an artificial sensorium of sight, sound and touch. (...) It is actually an interactive system as the computer that creates the simulated environment in which a person is immersed, constantly reconfigures the environment in response to body movements. (...) Therefore it can be said that VR is a medium which simulates a sense of presence through the use of technology (Featherstone \& Burrows, 1995: p. 6).

The applied technology allows one to feel present in a virtually created environment. "The computer must generate a convincing simulation of the look, feel, and sound of another environment. The eyes, ears, hands, and inner proprioceptive senses receive electromechanical stimuli that attempt to simulate a world pressing upon the senses" (Biocca, 1992: p. 27). - You are in it, my Dear. In this sense, immersion becomes equal to the feeling of presence in a computer-generated world. It is "the degree to which a virtual environment submerges the perceptual system of the user in virtual stimuli" and " $\mathrm{t}]$ he more the system captivates the senses and blocks out stimuli from the physical world, the more the system is considered immersive (ibid., p. 25). Interestingly, both, entities to interact with and a user hirself, become virtual, cyber entities in the virtual environment (Heim, 1995: p. 70). - You are immersed, you are present, yet, you are transformed and so is the world around you. A user and the world are both simulation (Heim, 1993). Apparently, a user can distinguish the real from the simulated. According to the elsewhere mentioned Burnett, "the human brain recognizes what's real and not real" (2016: p. 100). Nonetheless, in VR a user is immersed, present and so interacts, thinks, feels and acts. The question, most interesting and challenging one I would say, concerns precisely thoughts, feelings and actions that are (or can be) born on the crossroads of the real and simulated (and it of course matters what is simulated/created). But the answer is far from simple and requires further research. Yet, it can be expected that the interactions in VR may challenge and boost the ways one think, feels and acts. 
Certainly, it can occur in a real life too, but VR enables to create situations that cannot be easily experienced in real life or are impossible to experience. Thus, indeed VR may be seen as having "the potential to create an extremely reach perceptual and cognitive environment" and interactions "with such environment may tax mental capacities" (Shapiro \& McDonald, 1992: p. 104). I would suggest that the more interactive, changeable and unknown the VR is, the higher are the changes (for a user) to wonder, challenge and problematize meaning of the experienced external and internal sensations, be surprised, generate new meaning and ceaselessly dare it on the level of thinking, feeling and doing. And this could be, I dare say, because once the virtual world is created as an interactive, changeable, unfamiliar and unknown one then the immersion, which I define as a cyberspace's promise to possibly stimulate criticism and creativity among students, is in a sense doubled, namely, it is a sense of presence coupled with twists and turns, interaction, engagement, attention and (self-) curiosity. - You are Alice in Wonderland: the meaning is (always) in the making.

\section{Few Questions about the Praxis}

As I have argued in the preceding paragraph, immersion (i.e., sense of presence, twists and turns, interaction, engagement, attention and (self-) curiosity), which might be generated by cyberspace, can possibly surprise and make students wonder, and cause meaning to tremble concomitantly supporting students in becoming critical and creative. The pedagogical practices, which I encourage, are meant to, so to say, do the same. Therefore, I want to suggest that in order to actualize these practices online, perhaps, it is worthy trying to create/generate/ stimulate immersion. This means, design and combine content, teaching methods, learning activities, software and hardware in such way as to engender immersion. Yet, as argued elsewhere in this article, for these practices to result in students' critical-creative abilities, they should also try to understand-appreciatechallenge students' patterns of conceptualization and secure students' endurability and sustainability. Thus, content, teaching methods, learning activities, software and hardware apart from stimulating immersion, also need to mind students' patterns of meaning making, and their endurability. Therefore, the challenge now is to think about content, teaching methods, learning activities, software and hardware (and their combinations), which-in relation to the topics and issues that are planned to be addressed in a given class or/and programme-are able to engender sense of presence (as in VR, if possible), interactive, changeable, unknown, unfamiliar space full of twists and turns (i.e., transformations, becomings, metamorphoses) that keep one engaged, active, participatory, attentive, (self-) curious, surprised, lacking/finding/loosing/finding the meaning thus, ultimately critical and creative. Content, teaching methods, learning activities, software and hardware that will help understanding-appreciatingchallenging students' patterns of conceptualization, and will support them in dealing with either a lack of sense or new (sometimes unexpected) meaning of 
the self or of whatever there is that they experience. The latter is especially crucial as apparently too much of indetermination and too much of novelty might be unsustainable, namely, as it has been already said, it might be too much to take.

I dare say that interdisciplinary cooperation, true imagination and, indeed, creative thinking, are necessary to design (and combine) content, teaching methods, learning activities, software and hardware to have the effects outlined above. Indisputably, there could be many ways in which content, teaching methods, learning activities, software and hardware could be designed and combined. The more ideas, the better, and interdisciplinary cooperation is indispensable to form a platform on which those ideas can grow. As such, I do not want to provide clear-cut answers, but rather pose an invitation to think together on online pedagogical practices that can lead to immersion (in the sense outlined above), students' sustainability, and ultimately to criticism and creativity. However, to initiate the thinking process I want to suggest that, among many other possible ways, we could perhaps design and combine content, teaching methods, learning activities, software and hardware in such way that they will engender a Wonderland yet, a Wonderland that will help understanding-appreciatingchallenging students' patterns of conceptualization and entail landmarks of an "epistemic rest"?

Why a Wonderland? To me Wonderland, as imagined by Lewis Carroll, is:

1) an interactive space:

"'Begin at the beginning,' the King said gravely, 'and go on till you come to the end; then stop.";

"Why is a raven like a writing-desk?";

2) an unknown space:

“'What sort of people live about here?' 'In that direction,' the Cat said, waving its right paw round, 'lives a Hatter; and in that direction,' waving the other paw, 'lives a March Hare. Visit either you like: they're both mad."';

3) a full of twists and turns space:

“'it's no use going back to yesterday, because I was a different person then."

4) a space that keeps Alice engaged:

“'-so long as I get somewhere,' Alice added as an explanation. 'oh, you're sure to do that,' said the Cat, 'if you only walk long enough."';

5) surprised:

“How puzzling all these changes are! I'm never sure what I'm going to be, from one minute to another!"”;

6) (self-) curious:

"Let me think: was I the same when I got up this morning? I almost think I can remember feeling a little different. But if I'm not the same, the next question is, Who in the world am I? Ah, that's the great puzzle!'”;

"CCuriouser and curiouser.";

7) and in a constant search for meaning: 
“'Well! I've often seen a cat without a grin,' thought Alice, 'but a grin without a cat!"”;

"'Take care of the sense and the sounds will take care of themselves";

"it seemed quite dull and stupid for life to go on in the common way."

Can we then think about and imagine teaching methods, learning activities, software and hardware that can create Wonderlands for different topics/issues in various academic fields?

Wonderlands that will help understanding-appreciating-challenging students' patterns of conceptualization,

"We had the best of educations - in fact, we went to school every day- (...) And how many hours a day did you do lessons?" said Alice (...). "Ten hours the first day," said the Mock Turtle, "nine the next, and so on." "What a curious plan!" exclaimed Alice. "That's the reason they're called lessons," the Gryphon remarked, "because they lessen from day to day." This was quite a new idea to Alice and she thought it over a little before she made her next remark, "Then the eleventh day must have been a holiday?"

Wonderlands but with an "epistemic rest" that is moments when the familiar, the recognizable, the habitual comes to the fore so that students can experience, endure and welcome instants of indetermination and a new (never final) meaning,

Down, down, down. There was nothing else to do, so Alice soon began talking again. "Dinah'll miss me very much to-night, I should think!" (Dinah was the cat.) "I hope they'll remember her saucer of milk at tea-time. Dinah my dear! I wish you were down here with me! There are no mice in the air, I'm afraid, but you might catch a bat and that's very like a mouse, you know. But do cats eat bats, I wonder?" And here Alice began to get rather sleepy and went on saying to herself, in a dreamy sort of way, "Do cats eat bats? Do cats eat bats?" and sometimes, "Do bats eat cats?"

\section{So, Do bats eat cats?}

\section{DFI-Digital Facial Image}

The discussion on the DFI-Digital Facial Image is based on the article "Affect as medium, or the "digital-facial-image" (2003) by Mark B.N. Hansen. In this article, Hansen defines the DFI as "digitally generated close-up image of a face" able to engender an affective ${ }^{4}$ response in a viewer (2003: p. 206). In the encounter with the DFI the viewer "comes to function as the very medium for the interface between the embodied human and the domain of digital information" (Hansen, 2003: p. 206). Hansen sees the DFI as an advanced form of human-computer-

${ }^{4}$ In his discussion about affectivity, Hansen explicitly emphasizes his different to Deleuze (1986) take on affect. In this article, I, however, combine Hansen's approach to affect and affectivity with my reading of the Deleuzian and Guattarian concepts of affect and concept outlined in $A$ Thousand Plateaus (1987) and What is Philosophy? (2009). 
interface (HCI),

Whereas the HCI functions precisely be reducing the wide-bandwidth of embodied human expressivity to a fixed repertoire of functions and icons, the DFI transfers the site of this interface from computer-embodied functions to the open-ended positive feedback loop connecting the digital-facial-image and the entire affective register operative in the embodied viewer-participant. Thus, rather than channelling the body's contribution through the narrow frame of preconstituted software options, the DFI opens the interface to the richness of the bodily processing of information. For this reason, the DFI allows us to reconceptualize the very notion of the interface: by bypassing investment in more effective technical "solutions", it invests in the body's capacity to supplement technology-the potential it holds for "collaborating" with the information presented by the interface in order to create images. (ibid., p. 207)

In an encounter with the DFI the body becomes affected (the ability to become affected is the body's potential to collaborate with the information). In this sense, the DFI "forms the very vehicle of contact between our bodies and the domain of information that would otherwise remain largely without relations to us" (ibid., p. 208). Importantly, affectivity springs to life precisely during an encounter, "the crucial element is neither image nor body alone, but the dynamical interaction between them" (ibid., p. 208). It seems that above other images, an image of a face plays crucial role with regard to affectivity. Face, as Hansen argues after Deleuze and Guattari (1987), in capitalist semiotics has become a signifier of the entire body, and the body operates as a signifier because it 'has' a face or rather because it "has been entirely facialized" (Deleuze \& Guattari, 1987 in Hansen, 2003: p. 208). Yet, with the DFI a face, a "rich source for meaning and the precondition of communication," is sensu stricto a digital one, fundamentally heterogeneous from a "real" one (Hansen, 2003: p. 208). As such, it affects the body of the viewer, and it affects the body precisely because it [DFI] presents "radical heterogeneity to already developed human perceptual capacities" (Stern, 1985 in Hansen, 2003: p. 209). By affecting the body, the DFI allows the body a new experience, "opens embodied experience to that which does not conform to already contracted bodily habits" and "attune[s] the body to a stimulus that is novel" (Hansen, 2003: p. 207, 209). Importantly, this affection/affectivity "introduces the power of creativity into the sensorimotor body" (ibid., p. 208). To summarize: the contact between the digital and the corporeal is established through affectivity. The more different and alien an image is (or becomes, as the initial indiscernibility might be beneficial to affectivity); the less it is "of the same 'reality' as we are;" the odder the interaction between a viewer and an image is; the more a viewer's senses are challenged, the more intense becomes affectivity. To illustrate his argument, Hansen refers to some artistic works that use the DFI. He brings to the fore, among others, an example of an image of an artist kissing her boyfriend, whose face is not present (Inez van 
Lamsweerde, Me Kissing Vinoodh (Passionately), 1999); a virtual persona called Marie who is much more into self-reflection than into interaction with a viewer (Luc Corchesne, Portrait No. 1, 1990); an image that upon touch is replaced with a live video image of the viewer (Alba d'Urbano, Touch Me, 1995), or a digital female face who remains indifferent to a viewer's efforts to commence a conversation with her (Kirsten Geisler, Dream of Beauty 2.0, 1999). All those works, according to Hansen, result in an affective response of the viewer who may eventually e.g., experience the impossibility of connection, "cannot take it any longer," feel irrelevant, unnecessary and unimportant, or "see himself or herself as a transitory punctuation in the ongoing and inhuman digital flux" (ibid., p. 215).

I read the affective response of a viewer, which Hansen describes, (apart from the link it establishes between the body and the realm of digital) as both affect and concept; sensory and conceptual becoming. To me, an encounter with a radical difference embodied by the DFI results in indetermination, indiscernibility, surprise, and wonder (affect), but also in a new meaning (concept) concerning e.g., the self (irrelevance and unimportance of the viewer) or connection/interaction with the other (can one ever connect and/or comprehend/feel the other?). In this sense, I approach the DFI as able to generate criticism and creativity in a viewer. I see it as a tool that engenders wonder and surprise, but also allows one to challenge, problematize and conjure a new meaning (what is this? why is this? who am I? do I matter? why do I feel like that? what to do? can I see it like this?). The digital facial image apparently has a special potential to do so, mostly due to the fact that, as Hansen argues, it is a "face" thus, to repeat briefly, a "rich source for meaning and the precondition of communication." But because the face is digital, it, so to say, automatically becomes alien, and the less it communicates with the viewer in the expected, more obvious and habitual manners, the stronger are both an engendered affect and an evoked concept. Furthermore, because the DFI stands for an unknown and unfamiliar "space" it can also, I want to argue, create a sensation of immersion (as outlined in the preceding subchapter), and in this sense strengthen a viewer's ability to become critical and creative. Importantly, however, an encounter with the DFI, at least the way I see it, should not cause an exhaustion of the viewer. It is precisely the sustainability and endurance of the viewer that has to be taken under consideration and respected. The meaning interestingly disappears; is challenged; transforms; becomes, but it should not be thrown away and rejected, but rather faced with curiosity, with a desire for more. Think, feel and act differently_cyberspace may promise you that.

\section{Few Questions about the Praxis}

Since the DFI may apparently boost criticism and creativity in a viewer, can it then be used in online teaching and learning? What kinds of the DFI (in terms of software, hardware and the content/interaction/expression) can be useful for pedagogical practices (in various academic fields) that strive to make students 
wonder and generate a new meaning of the experienced external and internal sensations? How to incorporate and, so to say, combine the DFI with online teaching methods, learning activities and content so that students will learn to welcome surprise and lack of meaning; will accept, but also attempt to generate a new one, and ultimately will be able to sustain and endure the experienced indetermination and novelty? Since, as argued before, the pedagogical practices, which can hopefully lead to criticism and creativity, ought to help understanding-appreciating-challenging students' patterns of conceptualization, the DFI and the ways in which it is combined with teaching methods/learning activities/content should also aim at that.

Again, to bring answers to the questions posed above, and to actualize the DFI in teaching practices (if possible), interdisciplinary cooperation is crucial and indispensable. Therefore, once more, I voice an invitation for collective and cross-disciplinary thinking on online pedagogical practices, criticism and creativity and the DFI (digital facial image), which to me carries an incredible potential to positively and affirmatively affect a viewer-participant-student. There could be countless ways in which the DFI can be designed and combined with teaching methods/learning activities/content, and a wide range of forms of interaction between a digital face and a student. In my opinion, there are endless possibilities to teach creativity and criticism online, as conceptualized in this article, with the DFI, regardless the academic field and the addressed topics/issues. Yet, can we, at least, try to commence to imagine? And again, I will evoke the landscapes of the Wonderland - to me a blueprint for meaning-challenging interactions and a space of the radically different yet, affirmatively positive forms of embodiment.

Imagine, after a pre-recorded lecture, an encounter with the DFI who like the White Rabbit does not seem to notice or care about you, but who is with you nonetheless, and who leads though without really leading you. This DFI shows you hidden passages, possibilities, throws you gloves so you can learn to swim in the pool of your own tears and even win an everybody-winning Caucus-race, or leaves you in a room where you realize that "there's no room to grow up any more." The DFI remains indifferent, but interesting; magnetic-you do not want to run away, to the contrary, you want to open the doors, which the DFI is passing by, and if you are too small or too large there will be ways to reflect, measure and play with your own size. Or imagine, the Hatter/March Hare-like DFI just after an online seminar. Puzzling you about ravens and writing-desks (there are no easy answers). Staring with eyes wide shut at the meaning: “Then you should say what you mean,' the March Hare went on. 'I do,' Alice hastily replied, 'at least-at least I mean what I say-that's the same thing, you know.' 'Not the same thing a bit!' said the Hatter, 'You might just as well say that "I see what I eat" is the same thing as "I eat what I see"!' 'You might just as well say,' added the March Hare, "that "I like what I get" is the same thing as "I get what I like"!"” (wonder and a new meaning always on the move). Or accidently freezing 
time so that little-sustaining-one-habits are engendered (only to push the meaning forward): “'It's always six o'clock now.' A bright idea came into Alice's head. 'Is that the reason so many tea-things are put out here?' she asked. 'Yes, that's it,' said the Hatter with a sigh, 'it's always tea-time and we've no time to wash the things between whiles.' 'Then you keep moving round, I suppose?' said Alice. 'Exactly so,' said the Hatter, 'as the things get used up.' 'But what happens when you come to the beginning again?' Alice ventured to ask. 'Suppose we change the subject,' the March Hare interrupted (...)." Or the DFI who, just before an online meeting with a tutor, wants to know you concomitantly appreciating that you may possibly not know you yourself: "'Who am I then? Tell me that first, and then, if I like being that person, I'll come up: if not, I'll stay down here till I'm somebody else."'

So, what happens when you come to the beginning again?

\section{8. (Never) Final Thoughts}

Concepts of criticism and creativity may differ, and so can pedagogical undertakings that aim at supporting students in becoming critical and creative. My particular take on criticism and creativity, which I define as an ability to challenge and problematize meaning of the experienced external and internal sensations, to become surprised, to generate new meaning (i.e., new forms of thinking, feeling and acting), and to continually dare it, is one out of many possible. Likewise, the discussed pedagogical practices, and the manners, in which, they can be actualized in online education, are my very own-creative-suggestions, daring forms of affirmative imagination and attempts to challenge my conceptual frameworks concerning education in general, and online education in particular. Interestingly, immersion, the DFI and the landscapes of Wonderland seem to be useful ideas and concomitantly beneficial tools which can be used when criticism and creativity in online education is at stake. Yet, neither the proposed concept of criticism-creativity nor the ways in which criticism and creativity might be promoted are final and ultimate. Furthermore, there are also many questions-concerning content, teaching methods, learning activities, software, hardware, and their combinations in online education-that still beg answers. Therefore, believing that the meaning is always in the making, I am interested in and open to a continuous exercise of problematizing and complexifying an understanding of criticism and creativity, and discussing the possibilities of teaching and learning criticism and creativity in online educational context. I am also strongly committed to a constant exploration of the promises that cyberspace may offer, and the possible actualization of its potential in online pedagogical endeavours.

So here it is, an article that perhaps stands for a slight Wonderland with an island of the epistemic rest itself. Namely, it brings to the fore certain concepts and suggestions concomitantly inviting myself, the author, and readers to never cease undertaking theoretical endeavours and daring imagining innovative prac- 
tices which ultimately can be applied.

\section{Statement}

This article has been written during the author's stay as a visiting researcher at Deusto International Tuning Academy (Short-Term Visits Scholarship Scheme), University of Deusto, Bilbao, Spain.

\section{Conflicts of Interest}

The author declares no conflicts of interest regarding the publication of this paper.

\section{References}

Balsamo, A. (1996). Technologies of the Gendered Body: Reading Cyborg Women. Durham and London: Duke University Press.

Barrett, L. F., Wilson-Mendenhall, C. D., \& Barsalou, L. W. (2014). A Psychological Construction Account of Emotion Regulation and Dysregulation: The Role of Situated Conceptualizations. In J. J. Gross (Ed.), The Handbook of Emotion Regulation (2nd ed., pp. 447-465). New York: Guilford.

Barrett, L. F. (2012). Emotions Are Real. Emotion, 12, 413-429. https://doi.org/10.1037/a0027555

Barrett, L. F. (2009). The Future of Psychology: Connecting Mind to Brain. Perspectives on Psychological Science, 4, 326-339. https://doi.org/10.1111/j.1745-6924.2009.01134.x

Barrett, L. F. (2006). Solving the Emotion Paradox: Categorization and the Experience of Emotion. Personality and Social Psychology Review, 10, 20-46. https://doi.org/10.1207/s15327957pspr1001_2

Barsalou, L. W. (2009). Simulation, Situated Conceptualization, and Prediction. Philosophical Transactions of the Royal Society B: Biological Sciences, 364, 1281-1289. https://doi.org/10.1098/rstb.2008.0319

Bejerano, A. R. (2008). The Genesis and Evolution of Online Degree Programs: Who Are They for and What Have We Lost along the Way? Communication Education, 57, 408-414. https://doi.org/10.1080/03634520801993697

Benedikt, M. (Ed.) (1992). Cyberspace: First Steps. Cambridge: The MIT Press.

Biocca, F. (1992). Virtual Reality: A Tutorial. Journal of Communication, 42, 23-72. https://doi.org/10.1111/j.1460-2466.1992.tb00811.x

Boler, M. (2002). The New Digital Cartesianism: Bodies and Spaces in Online Education. Philosophy of Education, 331-340.

Bukatman, S. (1993). Terminal Identity. The Virtual Subject in Postmodern Science Fiction. London: Duke University Press.

Burnett, D. (2016). Idiot Brain. What Your Head Is Really Up To? New York: W. W. Norton \& Company.

Carroll, L. (1865). Alice's Adventures in Wonderland. London: Macmillan Publishers.

Citron, D. K. (2009). Law's Expressive Value in Combating Cyber Gender Harassment. Michigan Law Review, 108, 373-416.

http://digitalcommons.law.umaryland.edu/cgi/viewcontent.cgi?article=1687\&context=f ac_pubs 
Cobb, S. C. (2009). Social Presence and Online Learning: A Current View from a Research Perspective. Journal of Interactive Online Learning, 8, 241-254.

Deleuze, G., \& Guattari, F. (2009). What Is Philosophy? London and New York, NY: Verso.

Deleuze, G., \& Guattari, F. (1987). A Thousand Plateaus. Capitalism and Schizophrenia. London and New York, NY: Continuum.

Deleuze, G. (1986). Cinema 1: The Movement-Image. Minneapolis, MN: University of Minnesota Press.

Featherstone, M., \& Burrows, R. (1995). Cyberspace, Cyberbodies, Cyberpunk. Cultures of Technological Embodiment. London: SAGE Publications.

Frisby, B. N., Limperos, A. M., Record, R. A., Downs, E., \& Kercsmar, S. E. (2013). Students' Perceptions of Social Presence: Rhetorical and Relational Goals across Three Mediated Instructional Designs. MERLOT Journal of Online Learning and Teaching, 9, 468-480.

Gvaramadze, I. (2012). Developing Generic Competences in Online Virtual Education Programmes at the University of Deusto. Campus-Wide Information Systems, 29, 4-20. https://doi.org/10.1108/10650741211192028

Hansen, M. B. N. (2003). Affect as Medium, or the "Digital-Facial-Image". Journal of Visual Culture, 2, 205-228. https://doi.org/10.1177/14704129030022004

Heim, M. (1995). The Design of Virtual Reality. In M. Featherstone, \& R. Burrows (Eds.), Cyberspace, Cyberbodies, Cyberpunk. Cultures of Technological Embodiment (pp. 66-77). London: SAGE Publications. https://doi.org/10.4135/9781446250198.n4

Heim, M. (1993). The Metaphysics of Virtual Reality. Oxford: Oxford University Press.

Henriksen, L. (2016). In the Company of Ghosts. Hauntology, Ethics, Digital Monsters. PhD Dissertation, Linköping: Linköping University Press.

Just, E. (2016). Daring to Dare-Theoretical Experiment for Pedagogical Practices and Body-Brain-Embedded Subject. Creative Education, 7, 293-301. https://doi.org/10.4236/ce.2016.72028

Kee, J. (2005). Cultivating Violence through Technology? Exploring the Connections between Information Communication Technologies (ICT) and Violence against Women $(V A W)$. The Association for Progressive Communications. http://www.genderit.org/sites/default/upload/VAW_ICT_EN.pdf

Land, R., \& Bayne, S. (2011). Digital Difference. Perspectives on Online Learning. Rotterdam: Sense Publishers. https://doi.org/10.1007/978-94-6091-580-2

Land, R., \& Bayne, S. (2005). Education in Cyberspace. London and New York, NY: Routledge.

Land, R. (2004). Issues of Embodiment and Risk in Online Learning. In R. Atkinson, C. McBeath, D. Jonas-Dwyer, \& R. Phillips (Eds.), Beyond the Comfort Zone: Proceedings of the 21st ASCILITE Conference (pp. 530-538). Perth, 5-8 December 2004. http://www.ascilite.org.au/conferences/perth04/procs/land.html

Leslie, I. (2014). Curious: The Desire to Know and Why Your Future Depends on It. Toronto: House of Anansi Press.

Lindquist, K. A., Wager, T. D., Kober, H., Bliss-Moreau, E., \& Barrett, L. F. (2012). The Brain Basis of Emotion: A Meta-Analytic Review. Behavioral and Brain Sciences, 35, 121-202. https://doi.org/10.1017/S0140525X11000446

Lindquist, K. A., \& Barrett, L. F. (2012). A Functional Architecture of the Human Brain: Insights from Emotion. Trends in Cognitive Sciences, 16, 533-540. 
https://doi.org/10.1016/j.tics.2012.09.005

Lowenthal, P. (2009). The Evolution and Influence of Social Presence Theory on Online Learning. In T. T. Kidd (Ed.), Online Education and Adult Learning: New Frontiers for Teaching Practices (pp. 124-139). Hershey, PA: IGI Global,

Lowenthal, P., \& Parscal, T. (2008). Teaching Presence Online Facilitates Meaningful Learning. The Learning Curve, 3, 1-11.

Løvlie, L. (2005). Is There Any Body in Cyberspace? or the Idea of a Cyberbildung. Utbildning \& Demokrati, 14, 115-130.

Nunes, M. (1997). What Space Is Cyberspace? The Internet and Virtuality. In D. Holmes (Ed.), Virtual Politics. Identity and Community in Cyberspace (pp. 163-179). London: SAGE Publications.

Robins, K. (1995). Cyberspace and the World We Live In. In M. Featherstone, \& R. Burrows (Eds.), Cyberspace, Cyberbodies, Cyberpunk. Cultures of Technological Embodiment (pp. 135-157). London: SAGE Publications. https://doi.org/10.4135/9781446250198.n8

Rourke, L., erson, T., Garrison, D. R., \& Archer, W. (1999). Assessing Social Presence in Asynchronous Text-Based Computer Conferencing. Journal of Distance Education, 14, 50-71.

Rovai, A. A. P. (2002). A Preliminary Look at the Structural Differences of Higher Education Classroom Communities in Traditional and ALN Courses. JALN, 6, 41-56.

Russell, J. A. (2003). Core Affect and the Psychological Construction of Emotion. Psychological Review, 110, 145-172. https://doi.org/10.1037/0033-295X.110.1.145

Shapiro, M., \& McDonald, D. (1992). I Am Not a Real Doctor, But I Play One in Virtual Reality: Implications of Virtual Reality for Judgments about Reality. Journal of Communication, 42, 94-114. https://doi.org/10.1111/j.1460-2466.1992.tb00813.x

Siwak, W. (1997). Wirtualna rzeczywistość-ucieczka czy wyzwolenie? In S. Krzemień-Ojak (Ed.), Kultura i Sztuka u progu XXI wieku (pp. 43-54). Białystok: WydawnictwoTrans-Humana.

Sobchack, V. (1995). Beating the Meat/Surviving the Text, or How to Get Out of This Century Alive. In M. Featherstone, \& R. Burrows (Eds.), Cyberspace, Cyberbodies, Cyberpunk. Cultures of Technological Embodiment (pp. 205-215). London: SAGE Publications. https://doi.org/10.4135/9781446250198.n12

Stack, S. (2015). Learning Outcomes in an Online vs. Traditional Course. International Journal for the Scholarship of Teaching and Learning, 9, 1-18. https://doi.org/10.20429/ijsotl.2015.090105

Stern, D. (1985). The Interpersonal World of the Infant: A View from Psychoanalysis and Developmental Psychology. New York, NY: Basic Books.

Stone, R. (1992). Will the Real Body Please Stand Up? In M. Benedikt (Ed.), Cyberspace: First Steps (pp. 81-118). Cambridge: The MIT Press.

Tu, Ch., \& McIsaac, M. (2002). The Relationship of Social Presence and Interaction in Online Classes. The American Journal of Distance Education, 16, 131-150. https://doi.org/10.1207/S15389286AJDE1603_2

Waaldijk, B., \& Just, E. (2010). Tuning Educational Structures in Europe. Reference Points for the Design and Delivery of Degree Programmes in Gender Studies. Bilbao: Universidad de Deusto. 